\title{
Behandeling van peniscarcinoom
}

\section{Voorbeeld van centralisatie?}

\author{
S. Horenblas ${ }^{1}$
}

Published online: 4 September 2017

(c) The Author(s) 2017. This article is an open access publication.

Samenvatting De concentratie van de behandeling van peniskankerpatiënten in het Antoni van Leeuwenhoek heeft zich in een periode van ongeveer 10 jaar voltrokken, zonder bemoeienissen van welke instantie dan ook. Deze ongedwongen verandering in de behandelpraktijk van urologen in Nederland is het resultaat van door collegae erkende expertise, gebaseerd op veelvuldig gepubliceerd en uitgedragen onderzoek. Deze concentratie heeft geresulteerd in: 1) De kwaliteit van de zorg is toegenomen en behoort wereldwijd tot de beste, afgaande op de overlevingscijfers. 2) De concentratie van patiënten heeft de mogelijkheden geschapen om onderzoek te doen naar: a) de effectiviteit van de behandeling, b) de introductie van nieuwe behandelingen en c) onderzoek naar de oorzaak van peniscarcinoom. Daarnaast heeft de concentratie van patiënten bijgedragen aan de wereldwijde discussie over centralisatie. De behandeling van het peniscarcinoom in ons land kan als voorbeeld dienen van hoe concentratie gunstig kan uitpakken voor de kwaliteit van de zorg. Als zodanig kan de behandeling dienen als een voorbeeld voor centralisatie bij andere typen tumoren, indien aan de voorwaarden van algemeen erkende expertise wordt voldaan.

Trefwoorden peniscarcinoom $\cdot$ centralisatie

Prof. dr. S. Horenblas

s.horenblas@nki.nl

1 afdeling Urologie, Antoni van Leeuwenhoek, Amsterdam, Nederland

\section{The treatment of penis cancer}

An example for centralization?

Abstract Within a period of 10 years we have witnessed a change in the referral pattern of penis cancer patients. Almost $75 \%$ of Dutch penis cancer patients are being referred to the Netherlands Cancer Institute Antoni van Leeuwenhoek. This was not due to a deliberate health policy, but a voluntary change due to recognized expertise based on extensive presentations and publications of the department. This concentration has resulted in: 1) Increase of the quality of care as seen by increased survival figures. 2) The concentration of penis cancer patients in one institute has led to analyses of the results of the various treatments and led to improvements of the treatment worldwide. 3) The concentration of patients was also instrumental in the initiation of research into the etiology of penis cancer and quality of life. The treatment of penis cancer in the Netherlands can be exemplary for the effects of centralization, assuming that the conditions for recognized expertise are present.

Keywords penis carcinoma $\cdot$ centralisation

\section{Introductie}

Het Antoni van Leeuwenhoek-huis werd in 1914 opgericht als eerst instelling in Nederland die zich louter en alleen met de behandeling van en onderzoek naar kanker bezighield. Uit dien hoofde was het van meet af aan al een instelling waar patiënten met zeldzame kwaadaardige tumoren, zoals melanoom, sarcoom en genitale tumoren naartoe werden verwezen.

Bij mijn aanstelling in 1988, als uroloog, was er dan ook ervaring met de behandeling van het peniscarcinoom. Er 
Tabel 1 Aantal patiënten met peniscarcinoom in het AVL.

\begin{tabular}{lllllll}
\hline & cohort 1 & cohort 2 & cohort 3 & cohort 4 & cohort 5 \\
& $1956-1987$ & $1988-1993$ & $1994-2000$ & $2001-2011$ & $2012-2016$ \\
\hline aantal patiënten & 97 & 55 & 164 & 628 & 401 \\
& $3 / \mathrm{jr}$ & $10 / \mathrm{jr}$ & $27 / \mathrm{jr}$ & $60 / \mathrm{jr}$ & $80 / \mathrm{jr}$ \\
\hline
\end{tabular}

was alleen nooit iets over opgeschreven. In de Nederlandse medische literatuur was er evenmin veel opgeschreven, afgaande op het archief van het Nederlands Tijdschrift voor Geneeskunde. Ook internationaal was de literatuur beperkt. In PubMed is éen publicatie te vinden die dateert uit 1900; pas 30 jaar later werd de volgende gepubliceerd. Tot aan 1984 verschenen niet meer dan gemiddeld 60 artikelen per jaar. Standaardbehandeling bestond uit een chirurgische resectie met flinke tumorvrije marges. In de praktijk kwam dit neer op een partiële of totale amputatie. Dat het peniscarcinoom naar de lymfeklieren in de lies metastaseert, was al vroeg bekend. Maar een lymfeklierdissectie van de lies stond in een kwaad daglicht als gevolg van de forse morbiditeit, die in de periode zonder antibiotica vaak met de dood eindigde.

Mijn belangstelling voor deze tumor is louter toevallig. Bij een van de eerste operatiebesprekingen als kersverse uroloog, in die tijd nog tezamen met de chirurgische collegae, vijf chirurgen, twee hals-hoofdchirurgen en twee gynaecologen, werd mij gevraagd of een lymfeklierdissectie van de lies zin had bij een patiënt met een peniscarcinoom en onverdachte liesklieren. Ik had geen idee en bedacht dat het zinvol zou zijn om de ervaringen uit het verleden te onderzoeken. Na een gedegen statusonderzoek had ik vier jaar later een antwoord, met dank aan al mijn voorgangers, die hun behandelingen en overwegingen vaak uitvoerig hadden genoteerd.

\section{Centralisatie?}

In tab. 1 staat het aantal patiënten met een peniscarcinoom dat het AVL bezocht in de jaren 1956 (toen een systematische registratie plaatsvond) tot en met 2016.

Tot aan 1994 is er een betrekkelijk stabiele stroom van een klein aantal patiënten. Dit begint te veranderen in 1994. Reden is de toenemende stroom aan presentaties en artikelen die vanuit het AVL worden gegeven respectievelijk geschreven. Behalve aan de behandeling van de primaire tumor wordt met name aandacht geschonken aan een risicoinschatting op basis waarvan een lymfeklierdissectie bij onverdachte klieren moet worden overwogen. De overwegingen worden ook internationaal bediscussieerd en leiden tot richtlijnen zowel in Nederland als daarbuiten.

Met de introductie van de schildwachtklierprocedure in 1994 wordt een geheel nieuwe en vruchtbare weg ingesla- gen. De zogeheten profylactische lymfeklierdissectie kan veilig worden vervangen door een minimaal invasieve ingreep, die een nieuwe stroom aan publicaties en patiënten oplevert.

Met een incidentie van ongeveer 120 patiënten per jaar in Nederland wordt $50-75 \%$ van de patiënten met een peniscarcinoom momenteel in het AVL behandeld.

\section{Effecten van concentratie}

Is de kwaliteit van de zorg door de concentratie beter geworden? Die vraag kan onomwonden bevestigend worden beantwoord. Twee aspecten van die zorg kunnen dit illustreren: de overleving en het type behandeling van de primaire tumor.

In een analyse door Rosa Djajadiningrat is gekeken of patiënten die in een latere fase zijn behandeld beter af zijn [1]. Bijna 1.000 patiënten met een minimale follow-up van twee jaar werden in vier cohorten van verschillende behandelperioden onderverdeeld. In fig. 1 zijn de KaplanMeyercurves te zien.

De analyse liet een significante verbetering zien van de overleving van het cohort dat tussen 2001 en 2012 was behandeld. Het betreft alleen patiënten met klinisch onverdachte klieren. De meest voor de hand liggende reden hiervoor is het gestandaardiseerde protocol voor de schildwachtklierprocedure van alle peniscarcinoompatiënten met een tumor $\geq \mathrm{T} 1 \mathrm{~b}$.

In een analyse van zeldzame tumoren in Europa staan ook de overlevingscijfers van het peniscarcinoom (tab. 2; [2]). Uit die analyse blijkt de overleving in Nederland de hoogste te zijn van alle landen.

In een ander artikel van Rosa Djajadiningrat wordt de behandeling van de primaire tumor geanalyseerd [3]. Twee aspecten werden hierbij onder de loep genomen. Ten eerste in hoeverre er sparend werd geopereerd en ten tweede of deze sparende ingreep de overleving nadelig beïnvloedt. In een periode van ongeveer 40 jaar blijkt de kans op een amputatie bij een patiënt met een T1-T2-tumor afgenomen van ongeveer $70 \%$ tot iets minder dan $40 \%$. En hoewel het risico op een lokaal recidief groter wordt, heeft zo'n recidief geen gevolg voor de overleving. De sparende ingreep is dan ook de standaardingreep geworden. Met het sparen van de penis zijn ook de reconstructieve mogelijkheden toegenomen, zoals het gebruik van een huidtransplantaat 
Figuur 1 Kaplan-Meyercurves van de vier cohorten na een follow-up van twee jaar. cN0-patients: 1956-1987: $85 \%$; 1988-1993: $78 \%$; 1994-2000: 89\%; 2001-2012: $92 \%$.

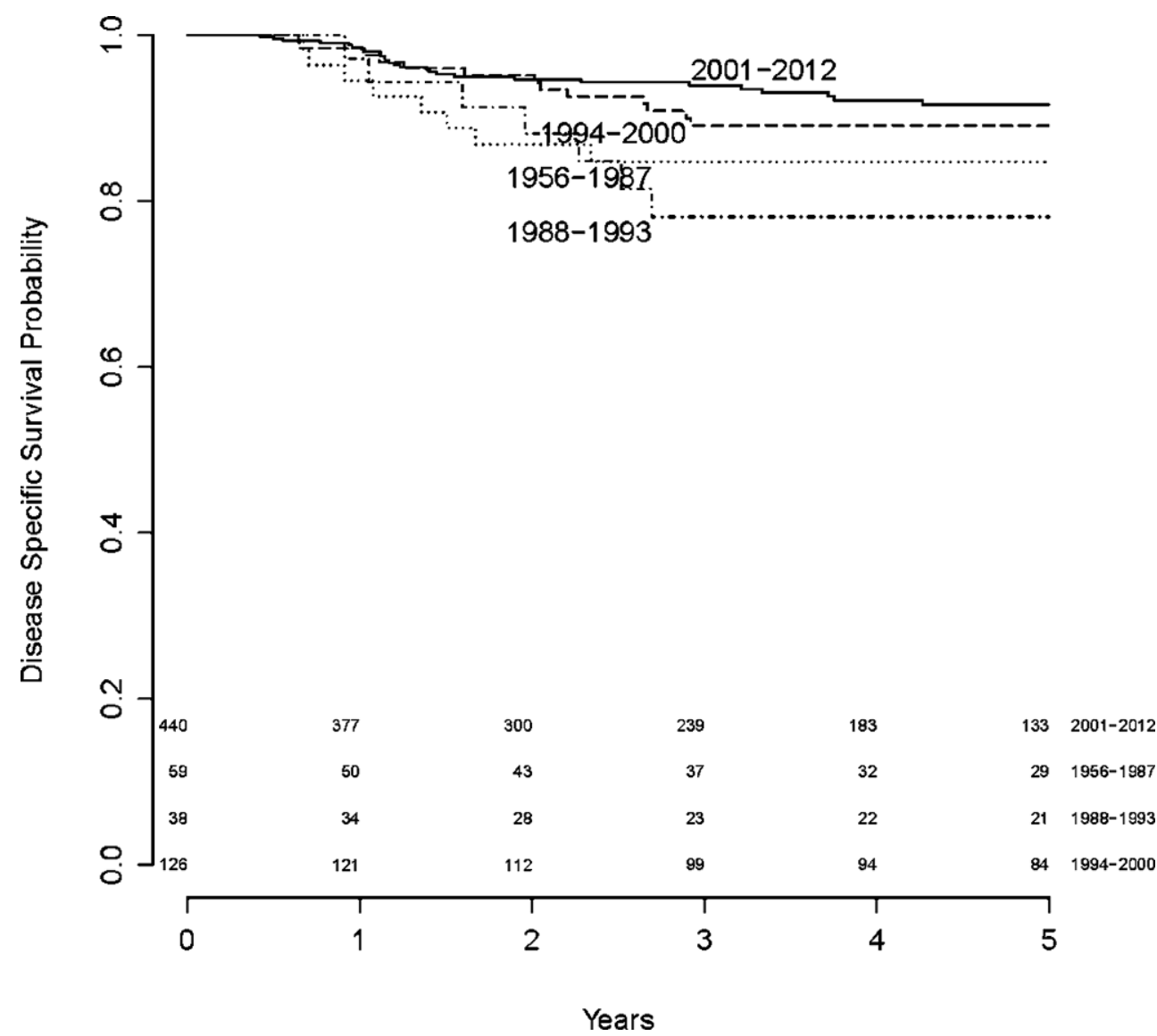

en het gebruik van de laser als adjuvante behandeling. De sparende ingrepen en de schildwachtklierprocedure vereisen een nauwgezette controle, teneinde recidieven in een zo vroeg mogelijk stadium op te sporen. Het vervolgschema hiervoor is gebaseerd op een analyse van het patroon van recidivering. Deze analyse door Joost Leijte is de basis geworden van een wereldwijd gehanteerd follow-upschema [4].

Kortom, de overleving is beter en de mutilatie is minder. Hiervoor verantwoordelijk is de combinatie van een grote gestage patiëntenstroom in een instelling met een cultuur voor analyse en vernieuwing, tezamen met gemotiveerde werknemers in alle geledingen van het instituut.

\section{Andere effecten van concentratie}

De analyse van de behandelgegevens uit het verleden en het prospectief bijhouden van de data, noodzaakte tot het opzetten van een aparte database, onafhankelijk van de routineregistratie van alle oncologische patiënten die standaard door de wetenschappelijke administratie in het AVL wordt verricht. Dit is de basis voor een alomvattende database in eigen beheer, die heden ten dage voor alle urologisch-oncologische patiënten wordt gebruikt, separaat van de centrale registratie. Real time kunnen behandelresultaten worden verkregen. Dit is de ideale setting voor een continue monitoring en feedback. Deze verworvenheid, aanvankelijk alleen voor het peniscarcinoom, heeft een natuurlijk gevolg gekregen voor alle tumoren. Er is een cultuur geschapen van permanente registratie door alle stafleden, fellows en assistenten. Permanent zijn er onderzoekers die toezicht houden op de database. De urologische database vormt het hart van het klinisch onderzoek en maakt nationale en internationale uitwisseling mogelijk.

Een grote continue patiëntenstroom met regelmatige analyses van de behandeling vergroot de motivatie om behandelingen die plaatsvinden binnen klinisch onderzoek, te verbeteren. Voorbeelden daarvan zijn de neoadjuvante behandeling bij lokaal geavanceerde stadia, de chemoradiatie voor dezelfde stadia en de introductie van de robotgeassisteerde liesklierdissectie [5, 6]. De behandelresultaten van de hogere stadia is maar matig en er is meer dan genoeg ruimte voor verbetering. Dat geldt ook voor de morbiditeit van de liesklierdissectie, die uitgebreid is geanalyseerd [7].

Ook diverse vormen van beeldvorming zijn onderwerp van onderzoek geweest, zoals de rol van de CT-scan, de rol van de echo en de rol van de PET-CT [8-14]. Ook het gebruik van een hybride tracer en navigatie is onderwerp van onderzoek geweest [15-18]. 
Tabel 2 Analyse van zeldzame tumoren in Europa na 1 en 5 jaar relatieve overleving (95\%-betrouwbaarheidsinterval), gestandaardiseerd naar leeftijd [2].

\begin{tabular}{lll}
\hline country & one year & five years \\
\hline Denmark & $84,2(78,8-89,8)$ & $70,2(61,8-79,6)$ \\
Finland & $87,4(79,0-96,6)$ & $65,2(52,5-80,9)$ \\
Iceland & - & - \\
Norway & $92,7(88,0-97,6)$ & $81,1(71,8-91,5)$ \\
Sweden & $84,8(80,4-89,5)$ & $68,5(61,6-76,2)$ \\
Ireland & $81,2(73,3-90,0)$ & $76,1(64,0-90,4)$ \\
UK England & $87,2(85,2-89,1)$ & $74,9(71,6-78,3)$ \\
UK Northern Ireland & $84,7(75,1-95,5)$ & $64,6(50,1-83,3)$ \\
UK Scotland & $82,8(76,9-89,2)$ & $62,6(53,4-73,5)$ \\
UK Wales & $87,9(81,1-95,3)$ & $65,3(54,1-78,8)$ \\
Austria & $86,3(80,5-92,5)$ & $75,0(64,7-86,9)$ \\
Belgium & $92,2(86,4-98,4)$ & $76,3(65,7-88,5)$ \\
France & $86,2(77,5-95,8)$ & $68,9(55,0-85,4)$ \\
Germany & $95,1(85,2-106,1)$ & $80,5(60,1-107,6)$ \\
Nehterlands & $95,2(90,5-100,2)$ & $88,3(78,3-99,4)$ \\
Switzerland & $91,8(83,8-100,5)$ & $71,1(57,2-88,3)$ \\
Italy & $88,9(85,9-92,0)$ & $73,7(68,7-79,1)$ \\
Malta & $67,5(58,9-77,4)$ & $62,9(49,2-80,4)$ \\
Portugal & $91,6(83,9-100,0)$ & $75,1(62,1-90,9)$ \\
Slovenia & $82,1(68,5-98,3)$ & $63,3(43,9-91,1)$ \\
Spain & $89,0(83,9-94,5)$ & $72,1(63,1-82,5)$ \\
Czech Republic & $72,7(55,9-94,7)$ & - \\
Poland & $67,5(53,8-84,7)$ & - \\
EUROPE & $86,8(84,9-88,8)$ & $72,9(70,5-75,5)$ \\
\hline & &
\end{tabular}

Niet door ons onderzocht, maar wel aannemelijk, is het gemak van overdracht van kennis en kunde op een afdeling waar ruime expertise aanwezig is over de behandeling van een tumortype. Deze 'cultuur van ervaring' is in mijn persoonlijke beleving dan ook behulpzaam bij het snel doorlopen van een leercurve.

Dan is er het bystanderfenomeen. Ervaringen bij het ene tumortype hebben invloed op de behandeling van andere tumortypen, denk aan de introductie van de schildwachtklierprocedure bij alle andere urologische tumoren [19]. De analogieën tussen het peniscarcinoom en andere genitale tumoren is een vruchtbare basis geworden voor onderzoek naar de relatie tussen immuniteit en het humane papillomavirus (HPV) [20, 21].

De resultaten van de behandeling in Nederland en het besef dat concentratie in een instituut met daarvoor geschikte infrastructuur daaraan wellicht debet zijn geweest, heeft internationaal tot centralisatieinitiatieven geleid.

Engeland heeft zogeheten supraregionale netwerken gecreëerd. Voor peniscarcinoom zijn de aanbevelingen als volgt geformuleerd: "Treatment should be provided supraregionally to populations of 4 million or greater who treat over 25 cases of penis cancer each year." Met deze doelstelling zouden acht tot tien centra moeten volstaan [22]. Een recente analyse naar de effectiviteit hiervan leidt tot resultaten die we in Nederland ook hebben gezien: meer weefselsparende behandelingen en betere overleving [23].

In Denemarken en Zweden is een aantal ziekenhuizen aangewezen voor de zorg voor patiënten met peniscarcinoom, zoals in Århus, Denemarken en in Örebro (Zweden). De betrokken urologen zijn al een tijd werkzaam geweest op het terrein van het peniscarcinoom. Een aantal is een tijd als gast en fellow in het AVL werkzaam geweest. Met Zweden heeft het AVL eens per maand een videoconferentie.

De centralisatie, verbetering van de behandeling, belangstelling voor immuniteit en het HPV hebben internationaal tot een belangrijke stroom aan publicaties geleid. Na 1984 is het gemiddelde aantal publicaties in PubMed van 60 gestegen naar 200. Nederland heeft daar ruim aan bijgedragen.

\section{Conclusie}

De concentratie van de behandeling van patiënten met een peniscarcinoom in één instituut heeft geleid tot een verbetering van de zorg, die zich weerspiegelt in meer weefselsparende ingrepen en een betere overleving. De rol die het AVL heeft gespeeld, is nationaal en internationaal erkend en heeft veel opvolging gekregen. Daarnaast bood de concen- 
tratie van patiënten de mogelijkheid voor onderzoek. Als zodanig kan de concentratie van peniscarcinoompatiënten dienen als een voorbeeld voor centralisatie bij de behandeling van andere urologische tumoren.

Dankbetuiging Met dank aan alle onderzoekers, medewerkers en stafleden. Zonder hun bijdrage was het succes van de behandeling van het peniscarcinoom onmogelijk geweest.

Open Access This article is distributed under the terms of the Creative Commons Attribution 4.0 International License (http:// creativecommons.org/licenses/by/4.0/), which permits unrestricted use, distribution, and reproduction in any medium, provided you give appropriate credit to the original author(s) and the source, provide a link to the Creative Commons license, and indicate if changes were made.

\section{Literatuur}

1. Djajadiningrat RS, Graafland NM, Werkhoven E van, et al. Contemporary management of regional nodes in penile cancer-improvement of survival? J Urol. 2014;191(1):68-73.

2. Visser O, Adolfsson J, Rossi S, et al. Incidence and survival of rare urogenital cancers in Europe. Eur J Cancer. 2012;48(4):456-64.

3. Djajadiningrat RS, Werkhoven E van, Meinhardt W, et al. Penile sparing surgery for penile cancer-does it affect survival? J Urol. 2014;192(1):120-5.

4. Leijte JA, Kirrander P, Antonini N, et al. Recurrence patterns of squamous cell carcinoma of the penis: recommendations for follow-up based on a two-centre analysis of 700 patients. Eur Urol. 2008;54(1):161-8.

5. Leijte JA, Kerst JM, Bais E, et al. Neoadjuvant chemotherapy in advanced penile carcinoma. Eur Urol. 2007;52(2):488-94.

6. Djajadiningrat RS, Bergman AM, Werkhoven E van, et al. Neoadjuvant taxane-based combination chemotherapy in patients with advanced penile cancer. Clin Genitourin Cancer. 2015;13(1):44-9.

7. Stuiver MM, Djajadiningrat RS, Graafland NM, et al. Early wound complications after inguinal lymphadenectomy in penile cancer: a historical cohort study and risk-factor analysis. Eur Urol. 2013;64(3):486-92.

8. Djajadiningrat RS, Teertstra HJ, Werkhoven E van, et al. Ultrasound examination and fine needle aspiration cytology-useful for followup of the regional nodes in penile cancer? J Urol. 2014;191(3):652-5.

9. Graafland NM, Valdes Olmos RA, et al. 18F-FDG PET/CT for monitoring induction chemotherapy in patients with primary inoperable penile carcinoma: first clinical results. Eur J Nucl Med Mol Imaging. 2010;37(8):1474-80.

10. Leijte JA, Graafland NM, Valdes Olmos RA, et al. Prospective evaluation of hybrid 18F-fluorodeoxyglucose positron emission tomo- graphy/computed tomography in staging clinically node-negative patients with penile carcinoma. BJU Int. 2009;104(5):640-4.

11. Graafland NM, Leijte JA, Valdes Olmos RA, et al. Scanning with 18F-FDG-PET/CT for detection of pelvic nodal involvement in inguinal node-positive penile carcinoma. Eur Urol. 2009;56(2):339-45.

12. Kroon BK, Horenblas S, Deurloo EE, et al. Ultrasonography-guided fine-needle aspiration cytology before sentinel node biopsy in patients with penile carcinoma. BJU Int. 2005;95(4):517-21.

13. Horenblas S, Kroger R, Gallee MP, et al. Ultrasound in squamous cell carcinoma of the penis; a useful addition to clinical staging? A comparison of ultrasound with histopathology. Urology. 1994;43(5):702-7.

14. Horenblas S, Van Tinteren H, Delemarre JF, et al. Squamous cell carcinoma of the penis: accuracy of tumor, nodes and metastasis classification system, and role of lymphangiography, computerized tomography scan and fine needle aspiration cytology. J Urol. 1991;146(5):1279-83.

15. Brouwer OR, Buckle T, Vermeeren L, et al. Comparing the hybrid fluorescent-radioactive tracer indocyanine green-99mTc-nanocolloid with $99 \mathrm{mTc}$-nanocolloid for sentinel node identification: a validation study using lymphoscintigraphy and SPECT/CT. J Nucl Med. 2012;53(7):1034-40.

16. Brouwer OR, Berg NS van den, Matheron HM, et al. A hybrid radioactive and fluorescent tracer for sentinel node biopsy in penile carcinoma as a potential replacement for blue dye. Eur Urol. 2014;65(3):600-9.

17. Berg NS van den, Buckle T, Kleinjan GI, et al. Hybrid tracers for sentinel node biopsy. J Q Nucl Med Mol Imag. 2014;58(2):193-206.

18. KleinJan GH, Berg NS van den, Oosterom MN van, et al. Toward (hybrid) navigation of a fluorescence camera in an open surgery setting. J Nucl Med. 2016;57(10):1650-3.

19. Brouwer OR, Poel HG van der, Bevers RF, et al. Beyond penile cancer, is there a role for sentinel node biopsy in urological malignancies? Clin Transl Imaging. 2016;4(5):395-410.

20. Ottenhof SR, Djajadiningrat RS, Jong J de. Expression of programmed death ligand 1 in penile cancer is of prognostic value and associated with HPV status. J Urol. 2017;197(3 Pt 1):690-7.

21. Djajadiningrat RS, Horenblas S, Heideman DA, Sanders J, et al. Classic and nonclassic HLA class I expression in penile cancer and relation to HPV status and clinical outcome. J Urol. 2015;193(4):1245-51.

22. Singh R, James ND, Watkin NA. Future development of penile cancer services in the UK. BJU Int. 2004;94(7):967-9.

23. Bayles AC, Sethia KK. The impact of improving outcomes guidance on the management and outcomes of patients with carcinoma of the penis. Ann R Coll Surg Engl. 2010;92(1):44-5.

Prof. dr. S. Horenblas uroloog, hoogleraar urologie 